\title{
8 \\ SEDEKAH LAWANG AGUNG SEBAGAI EKSPRESI RASA SYUKUR MASYARAKAT DESA PERNEK
}

\author{
Mega Trishuta Pathiassana, Tesy Wahyuni Oktaviana \\ Received: 17 Juli 2021; Accepted: 27 Agustus 2021; Published: 28 September 2021 \\ Ed. 2021; 5 (1): 55 - 61
}

\begin{abstract}
This research aims to find out the origin and meaning of Sedekah Lawang Agung Ritual tradition was growth and developed among community of Pernek Village, Moyo Hulu Sub-district, Sumbawa Besar Regency. This qualitative study employed purposive sampling method with data collection technique by observation and in-depth interview from the informants. The result of this study showed that there were changes in meaning and objective of the tradition implementation. In the beginning, this tradition was intended for refusing reinforcements on plague afflicted the community. However, the meaning turned into gratitude expression for the community over time. On the other hand, this event is also used as culture and tradition promotion media of Pernek Village community impacted to tourism aspect nowadays. This aspect is expected to rise income of the community by economic activity included in part of the tourism activities.
\end{abstract}

Keywords: Pernek Village, Sedekah Lawang Agung, Sumbawa, Tradition.

\section{PENDAHULUAN}

Pertanian merupakan bagian kehidupan yang identik dari masyarakat Indonesia secara umum pada awalnya. Oleh karena itu, masyarakat Indonesia dahulunya dikenal juga sebagai masyarakat agraris. Hal ini pada akhirnya turut memengaruhi warisan budaya dan tradisi masyarakat Indonesia yang filosofi dan sebab-musababnya berkaitan dengan pertanian.

Secara umum, pertanian merupakan kegiatan untuk mengelola tumbuh-tumbuhan dan/ atau hewan secara sengaja untuk memperoleh hasilnya, baik yang telah diberikan oleh alam maupun dikembangbiakan (AARSTEN, 1953). Dari pengertian ini, pertanian bukan hanya berhubungan dengan kegiatan bercocok tanam saja, tetapi juga peternakan, perikanan, maupun kehutanan. Sedangkan, dalam arti yang lebih sempit, pertanian dapat dikatakan sebagai segala aspek biofisik yang berkaitan dengan usaha penyempurnaan budidaya tanaman untuk memperoleh produksi fisik yang maksimum (SuMANTRI, 1980).

Beberapa kepustakaan kuno menceritakan bawah kegiatan pertanian ditemukan oleh Kaisar Cina Shen Nung. Hal ini dimulai ketika ia mendapati rakyatnya menyukai makan daging sapi dan ayam yang diperolehnya dari hasil perburuan, serta mengumpulkan buah-buahan, biji-bijian, dan kacang-kacangan. Namun, semakin berjalannya waktu dan bertambahnya penduduk, lingkungan di sekitar masyarakat tidak dapat memberikan hasil alam yang cukup untuk mendukung kehidupan mereka. Oleh karena itu, ia menggagas suatu alat pengolah tanah dari sebilah kayu yang ditajamkan dan ditempelkan pada suatu tongkat. Itulah model bajak yang pertama 
yang ia perintahkan pada rakyatnya untuk digunakan pada kegiatan mengolah tanah dan bertanam jewawut yang tidak hanya digunakan untuk makanan sapi dan ayam.

Hingga kini, masih dapat ditemui tradisi di kalangan masyarakat Indonesia sendiri yang berkaitan dengan pertanian, terutama di kalangan masyarakat desa. Salah satu masyarakat yang masih mempertahankan budaya semacam ini adalah masyarakat Desa Pernek, Kecamatan Moyo Hulu, Kabupaten Sumbawa Besar.

Tradisi-tradisi budaya tersebut sampai saat ini masih dipertahankan, bahkan menjadi daya tarik wisata tersendiri bagi wilayah Sumbawa yang terus dipromosikan oleh dinas-dinas terkait. Tradisi-tradisi tersebut biasanya diadakan setiap tahun dan turut mengundang banyak wisatawan dari berbagai daerah dari dalam dan luar negeri. Selain itu, para awak media juga turut diundang untuk berpartisipasi agar dapat bersama-sama membantu memperkenalkan tradisi budaya Sumbawa ke khalayak yang lebih luas.

Sebut saja Ritual Sedekah Lawang Agung yang merupakan salah satu tradisi budaya yang cukup dikenal oleh masyarakat Sumbawa. Tradisi budaya ini hadir dan berkembang di wilayah Desa Pernek. Banyak yang menganggap bahwa awalnya ritual ini diadakan sebagai bagian dari ritual untuk meminta hujan kepada Sang Maha Pencipta sebelum aktivitas tanam di musim kemarau dimulai.

Di musim kemarau sendiri, jumlah curah hujan di daerah Sumbawa memang relatif sedikit. Ditambah lagi, peningkatan suhu pun dapat mencapai hingga lebih dari 40oC. Debit air di area pertanian juga semakin sedikit biasanya. Bahkan di beberapa wilayah desa, tidak sedikit sumur warga yang mengalami kekeringan. Kondisi-kondisi tersebut yang berpengaruh secara signifikan terhadap hasil produktivitas pertanian masyarakat. Di saat itulah biasanya Ritual Sedekah Lawang Agung diselenggarakan.
Akan tetapi seiring berjalannya waktu, tradisi ini hanya digunakan sebagai bagian dari festival budaya dan pariwisata. Tujuannya adalah agar warisan budaya ini tidak lantas menghilang dan tetap bertahan di antara masyarakat, utamanya bagi generasi muda. Selain, hal ini juga diharapkan dapat meningkatkan perolehan pendapatan masyarakat dari sisi pariwisata yang memiliki efek berganda bagi sektor lainnya.

Lebih dari sekadar itu, ritual ini juga memberikan beragam pembelajaran hidup bagi masyarakatnya. Salah satunya adalah sebagai ekspresi rasa syukur dan ajang silahturahim antara masyarakat di Desa Pernek dan sekitarnya.

\section{METODE PENELITIAN}

Metode yang digunakan dalam penelitian ini adalah studi pustaka dan lapangan. Studi pustaka dilakukan dengan melalui tinjauan pustaka yang bersumber dari sumber buku, artikel, dan jurnal ilmiah. Sedangkan, studi lapangan dilakukan dengan cara melakukan observasi dan wawacanra kepada beberapa informan.

Informan dalam penelitian ini dipilih menggunakan teknik purposive sampling, yaitu teknik pemilihan informan sebagai sumber data dengan pertimbangan tertentu sesuai dengan kebutuhan peneliti yang dilakukan secara sengaja (Sugiyono, 2016). Menurut Endaswara (2003), informan yang dipilih harus dapat memberikan informasi yang akurat kepada peniliti, serta terlibat langsung dan memiliki waktu untuk menjadi informan. Selain itu, penelitian ini merupakan penelitian kualitatif yang menghasilkan data deskriptif berupa catatan tertulis atau lisan dari para informan maupun perilaku yang dapat diamati (BogDAN, dkk., 1992).

Penelitian ini dimulai dengan beberapa tahapan, di antaranya observasi, wawancara, pendekatan penelitian, dan analisis data. Pendekatan yang digunakan dalam penelitian ini adalah pendekatan etnik (dari sudut pandang budaya_ yang memberikan pemahaman mengenai bagaiman budaya dari suatu daerah bekerja. Peneliti berperan sebagai 
pengamat dan cenderung meminta bantuan informan sebagai orang yang memahami budaya setempat untuk memberikan pemahaman ini, tetapi tidak berarti informan ini akan objektif, karena adanya kecenderungan informan yang terlalu ikut campur dan tidak objektif dalam memberikan penilaiannya.

Penelitian ini dilakukan di Desa Pernek, Kecamatan Moyo Hulu, Kabupaten Sumbawa Besar, Nusa Tenggara Barat. Desa Pernek memiliki 2 dusun, yaitu Dusun Pernek A dan B. Desa ini setiap tahunnya mengadakan tradisi Sedekah Lawang Agung sebelum masa tanam di musim kemarau yang diselenggarakan di area gerbang utama desa. Teknik pengumpulan data yang digunakan dalam penelitian ini adalah penelitian lapangan melalui metode observasi dan wawancara mendalam. Penelitian lapangan merupakan penelitian yang dilakukan secara sistematis dengan mengangkat data yang ada di lapangan (ARIKUNTO, 1995).

\section{HASIL DAN PEMBAHASAN Gambaran Umum Desa}

Desa Pernek merupakan salah satu dari 12 desa yang ada di Kecamatan Moyo Hulu, Kabupaten Sumbawa, Provinsi Nusa Tenggara Barat, Indonesia. Sebagian besar penduduknya bersuku Samawa dan bermatapencaharian petani. Terdapat satu lembaga pendidikan di desa tersebut, yaitu SD Negeri Pernek dengan jumlah guru PNS sebanyak 4 orang dan Non PNS sebanyak 5 orang.

Desa Pernek memiliki 4 dusun, 7 rukun warga, dan 15 rukun tetangga. Luas wilayah Desa Pernek sendiri sekitar 949,14 Ha yang terdiri dari luas pemukiman $102 \mathrm{Ha}$, luas perkebunan $35 \mathrm{Ha}$, luas pekarangan $25 \mathrm{Ha}$, luas pemakaman $3 \mathrm{Ha}$, luas persawahan $787 \mathrm{Ha}$, dan luas perkantoran 0,14 $\mathrm{Ha}$ dengan batas-batas wilayah, sebagai berikut:

1. Sebelah utara: Desa Boak, Kecamatan Unter Iwes.

2. Sebelah selatan: Desa Mokong, Kecamatan Moyo Hulu.
3. Sebelah timur: Desa Leseng, Kecamatan Moyo Hulu.

4. Sebelah barat: Desa Kerekeh, Kematan Unter Iwes.

Desa Pernek memiliki sekitar 1.839 orang yang terdiri dari 637 rumah tangga dengan rata-rata per rumah tangga memiliki sekitar 3 orang jiwa.

Desa ini merupakan salah satu desa yang berada di kawasan lingkar hutan yang dikelola oleh KPHP Batulanteh di antara dua olat (bukit), yaitu Okat Banga dan Olat Maras. Selain itu, Desa Pernek memiliki satu bendungan (Bendungan Pernek) yang juga berada di area ekowisata Air Terjun Teba Tewa yang dikembangkan oleh masyarakat setempat.

\section{Prosesi Ritual Sedekah Lawang Agung}

Ritual ini diawali dengan prosesi Liuk Desa (keliling kampung) sembari bersholawat dan memanjatkan doa-doa kepada Allah. Kemudian, dilanjutkan dengan ritual Bagi Bete (bete padi ketan dan bete jagung) sebagai simbol makanan pokok masyarakat Pernek yang dipimpin oleh istri pemuka adat dan agama selama dua hari berturut-turut menjelang maghrib, serta berlokasi di 4 sudut desa yang merupakan pintu keluar dan masuk desa, selain pintu gerbang utama desa.

Selanjutnya, kegiatan Mangan Rame (makan bersama-sama) menjadi tahapan ritual berikutnya yang dibuka oleh pemuka adat atau kepala desa. Bagian ini merupakan wujud untuk membangun kebersamaan antara warga desa dan para tamu yang hadir pada kegiatan tersebut. Ritual ini merupakan bagian utama yang sampai saat ini masih tetap berjalan dan dikenal juga dengan ritual tolak bala yang dilaksanakan pada hari ketiga setelah waktu Sholat Ashar di area gerbang utama desa. Pada bagian ini, ada makanan wajib yang harus disediakan, yaitu jangan bage (ikan yang diawetkan dengan asam) beserta nasi dan urap yang disajikan dengan tepi (tampah) yang diberi alas berupa ghodong poto (ujung daun pisang).

Ritual ini biasanya dilakukan menjelang musim 
hujan atau di sekitar Bulan September-Desember. Bagi para kaum tua, kegiatan ini akan dilakukan setelah Baseli Jarak atau memperhatikan daun jarak pagar yang di bulan sebelumnya tidak berdaun, tetapi jika sudah mulai tumbuh pucuk-pucuk daun baru, maka itulah pertanda pelaksanaan ritual Sedekah Lawang Agung ini akan diselenggarakan.

\section{Kisah Awal Mula Ritual Sedekah Lawang Agung Diselenggarakan}

Awalnya, ritual ini diselenggarakan oleh warga desa di zaman dulu (nenek moyang) dikarenakan adanya wabah yang ditandai dengan demam panas tinggi. Hal ini terjadi hampir di setiap kepala keluarga pada anak-anak usia 3-4 tahun yang terjadi secara bersamaan, sehingga wabah ini disebut dengan panas prana tau ode' (panas badan anak). Tidak adanya tenaga medis atau paramedic saat itu, membuat para orang tua kemudian membawa anak-anaknya yang sakit tersebut maupun yang tidak sakit secara berbondong-bondong ke 4 pintu gerbang desa terdekat bagi mereka untuk memanjatkan doa tolak bala. Di saat itu, anak-anak dibagikan bete' (sejenis makanan lokal seperti popcorn) sebagai penganan bagi mereka.

Pada peristiwa tersebut terjadi, iklim di sekitar desa sangatlah panas dan hal itu berdekatan dengan musim tanam padi sebagai makanan pokok masyarakat. Oleh karena itu, Sholat Istisqa' (Sholat Meminta Hujan) setelah Sholat Dzuhur dilaksanakan oleh masyarakat atas arahan pemuka agama desa. Hari pelaksanaan ditentukan oleh kesepakatan masyarakat yang bergantung pada lokasi penyelenggaraan kegiatan.

Biasanya 2 lokasi utama penyelenggaraan kegiatan, yaitu di dalam desa atau di sekitar sumber air yang ada di dekat area persawahan warga. Jika kegiatan dilakukan di dalam desa, maka Sholat Istisqa' dilakukan pada Hari Jun'at setelah Sholat Jum'at berjama'ah di masjid. Namun jika dilakukan di sekitar area persawahan, maka akan diselenggarakan pada Hari Sabtu pasca Sholat Dzuhur.
Makanan yang wajib disediakan adalah bubur yang terbuat dari beras, serta hanya ditambahkan dengan santan dan garam saja. Sedangkan, lauk-pauk tidak disediakan bersama bubur tersebut. Makanan ini akan disajikan untuk para jama'ah Sholat Istisqa' maupun warga yang hadir di sekitarnya.

Beberapa hari berikutnya pasca kegiatan tersebut di masa lampau, ada seorang kakek (papin) yang biasa dipanggil dengan Papin Musa, serta dianggap sebagai 'orang pintar' di antara masyarakat desa, mengarahkan mereka untuk mengadakan makan bersama di pintu gerbang utama dengan lauk jangan bage. Masyarakat desa, terutama para ibu dan anaknya, makan bersama atau saat ini disebut dengan istilah Mangan Rame di lokasi tesebut. Di saat itu pula, anak-anak yang menderita demam tinggi diberikan daun jarak pagar yang telah ditumbuk sebagai obat yang dibubuhi pada bagian ubunubun anak tesebut. Ritual inilah yang digunakan sebagai ritual tolak bala yang hingga saat ini disebut dengan Sedekah Lawang Agung.

\section{Pelaksanaan Ritual Sedekah Lawang Agung di Masa Kini}

Kegiatan ini sudah masuk ke dalam bagian festival budaya dan pariwisata setiap tahunnya yang diselenggarakan oleh Dinas Pariwisata Kabupaten Sumbawa. Kegiatan tetap dilakukan selama 3 hari dengan tidak meninggalkan budaya asli masyarakat Pernek. Namun, pada puncak kegiatan (makan bersama) turut mengundang masyarakat dari berbagai desa, bahkan para aparatur pemerintah daerah setempat.

Di sisi lain, pada bagian ritual Liuk Desa, masyarakat tidak hanya bersholawat, tetapi juga menggunakan rebana yang ditabuh oleh beberapa lelaki paruh baya sebagai pengiringnya. Masyarakat yang terlibat juga tampak menggunakan pakaian adat atau kere dua yang berwarna-warni. 


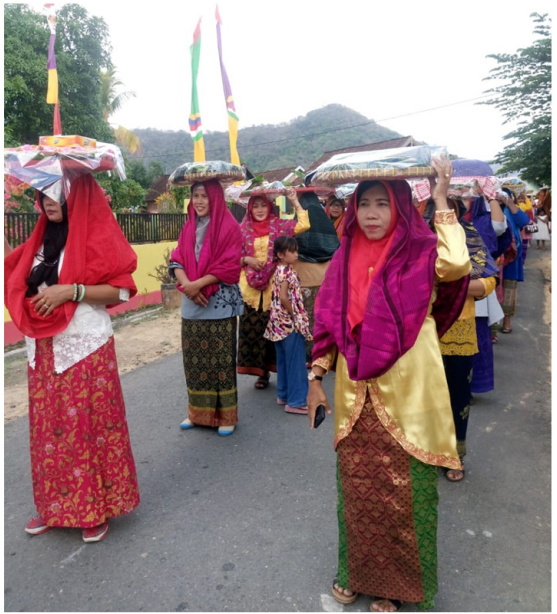

Gambar 1. Pawai Liuk Desa. Para wanita menggunakan kere dua sembari membawa 1 tepi/tampah yang berisi penganan khas Sumbawa.

Modifikasi juga terlihat pada tampilan sajian makanan dan tepi (tampah) yang digunakan lebih bervariasi dengan hiasan yang lebih semarak. Menu makanan yang dihidangkan juga lebih beragam, seperti sepat dan singang yang terbuat dari ikan, serta pelu aru sebagai lauk-pauknya.

Kegiatan Sedekah Lawang Agung saat ini juga diselenggarakan dalam satu rangkaian kegiatan bertajuk Suar Teja Raboran (Cahaya Pelangi Raboran). Raboran sendiri merupakan sebuah pegunungan di wilayah Kecamatan Moyo Hulu. Dahulu, tempat tersebut dijadikan sebagai padepokan untuk penggemblengan para pejuang kemerdekaan di Sumbawa. Kegiatan Suar Teja Raboran merupakan rangkaian festival budaya yang diselenggarakan oleh Pemerintah Kecamatan Moyo Hulu yang menggali nilai-nilai budaya dan tradisi yang ada di seluruh desa pada wilayah Kecamatan Moyo Hulu. Pada rangkaian festival ini, biasanya menampilkan pagelaran seni budaya yang mengangkat cerita rakyat dan atraksi, seperti Rabalas Lawas, Sakeco, Ngulang, Ratib, dan kolaborasi musik tradisional sebagai penutupnya.

\section{Makna dan Hikmah Ritual Sedekah La- wang Agung}

Berbeda dengan di zaman awal kegiatan ini diselenggarakan. Sedekah Lawang Agung bu- kan lagi diadakan sebagai kegiatan tolak bala, melainkan sebagai perwujudan rasa syukur masyarakat Desa Pernek kepada Allah. Hal ini dikarenakan wabah yang pernah terjadi sudah tidak ada lagi dan masyarakat patut untuk bersyukur atas hal itu. Namun, ritual ini tetap diadakan di sekitar waktu musim kemarau berkepanjangan atau peralihan antara musim kemarau dengan musim hujan (antara September hingga Desember).

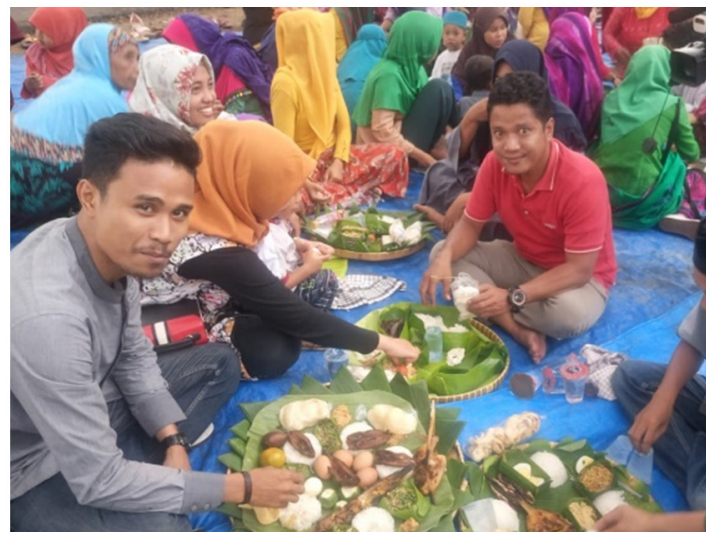

Gambar 2. Warga desa dengan para tamu melakukan Mangan Rame di area pintu gerbang utama desa yang menyajikan menu khas Sumbawa.

Kemudian, saat ini Sedekah Lawang Agung juga dijadikan sebagai ajang pertemuan para warga untuk memupuk tali silahturahim yang dilengkapi dengan doa bersama agar selalu diberikan kemudahan dan keberkahan rizki selama berusaha. Tradisi ini juga menghidangkan beragam jenis kuliner tradisional khas Sumbawa, seperti buras, petikal, onde-onde, topat dan beberapa penganan lainnya yang dapat dijadikan sebagai bagian pelestarian budaya di kalangan masyarakat Sumbawa, terutama generasi muda.

Selanjutnya, Sedekah Lawang Agung juga mengajarkan beberapa pelajaran hidup di antaranya, seperti:

1. Saling mengasihi dan memberi secara ikhlas, terepresentasi dari kegiatan saling berbagi makanan sesama warga dan juga menghidangkannya kepada seluruh tamu undangan.

2. Saling tolong-menolong dan bergotong 
royong, tampak dari proses persiapan kegiatan yang dilakukan bersama-sama oleh masyarakat, baik kaum muda maupun tua, bahu-membahu mempersiapkan penganan, pawai budaya, hingga malam pentas seni.

\section{KESIMPULAN}

Berdasarkan hasil analisis dan pembahasan, dapat ditarik kesimpulan bahwa Ritual Sedekah Lawang Agung yang diselenggarakan sebelum aktivitas tanam masyarakat Desa Pernek, Kecamatan Moyo Hulu, Kabupaten Sumbawa Besar, mulai mengalami perkembangan dan perubahan secara rangkaian kegiatan dan pemaknaannya.

Pada awalnya, ritual ini diadakan untuk menolak bala atas wabah penyakit yang terjadi di antara masyarakat desa. Hingga kini ritual tersebut terus berlanjut, tetapi beralih fungsi. Bukan lagi ditujukan sebagai ritual tolak bala, tetapi justru digunakan sebagai alat daya tarik wisata. Daya tarik wisata ini tidak hanya berguna bagi masyarakat Desa Pernek, tetapi juga masyarakat di wilayah Kabupaten Sumbawa Besar, bahkan Pulau Sumbawa pada umumnya. Aspek wisata ini yang diharapkan dapat meningkatkan perolehan pendapatan masyarakat di Sumbawa.

Selain itu, Ritual Sedekah Lawang Agung saat ini identik sebagai ekspresi rasa syukur masyarakat Desa Pernek dan ajang silahturahim di antara mereka. Makna lain yang diajarkan kepada kaum muda sebagai generasi penerus dari tradisi ini adalah tentang saling mengasihi, tolong-menolong, dan gotong-royong antar sesama.

Kegiatan ini sekarang diselenggarakan dalam rangkaian Festival Suar Teja Raboran yang diadakan di wilayah Kecamatan Moyo Hulu. Waktu penyelenggaraa dari festival ini biasanya dilakukan antara Bulan September-Desember di setiap tahunnya yang dihadiri oleh banyak pihak, termasuk wisatawan domestik maupun mancanegara.

\section{DAFTAR PUSTAKA}

Arikunto, S.

1995. Dasar-dasar Evaluasi Pendidikan.

Yogyakarta: Bumi Aksara.

Aarsten, J.V. (1953). Ekonomi Perta nian Indonesia. Jakarta:

Pembangunan.

Bogdan, Robert, \& Taylor, S.

1992. Pengantar Metode Kualitatif.

Surabaya: Usaha Nasional.

BPS Kabupaten Sumbawa.

2019. Kecamatan Moyo Hulu dalam Angka. https://sumbawakab.bps. go.id/. Diakses Desember 2020 pukul 03.08 WITA.

Diniyati, D., \& Achmad, B.

2020. Budaya Berladang Petani di Kesatuan Pengelolaan Hutan Produksi (KPHP) Batulanteh, Kabupaten Sumbawa. Jurnal Agroforestri Indonesia. Vol. 3, No. 1, Hal 19-28.

ENDRASWARA, S.

2003. Metodologi Penelitian Kebudayaan. Yogyakarta: Gadjah Mada University Press.

Kabupaten Sumbawa.

2017. Ritual Sedekah Lawang Agung, Budaya Syukur Masyarakat Pernek. https://infopublik.id/read/223761/ ritual-sedekah-lawang-agung-budayasyukur-masyarakat-pernek.html. Di akses Desember 2020 pukul 09.31 WITA.

Kementerian Kehutanan.

2012. Rencana Pengelolaan KPHP Batlanteh 2012-2022.http:/ /kph.menlhk. go.id/ sinpasdok/public/ RPHJP/1496039881RPHJP_KPHP_ BATULANTEH.pdf. Diakses

Desember 2020 pukul 02.59 WITA. 
Kusniadi, E.

. Modul 1 Pengertian dan Sejarah Perkem bangan Pertanian. http:/ / repository. ut.ac.id/4425/1/LUHT4219-M1.pdf. Diakses Desember 2020 pukul 02.18 WITA.

Musbiawan, $\mathrm{H}$.

Sejarah dan Perkembangan Islam di Sumbawa. Sumbawa: Dinas Perpusa takaan dan Kearsipan Kabupaten Sumbawa.

Priventa, $\mathrm{H}$.

2020. Tradisi Ziarah di Gua Maria Kendalisodo Kecamatan Bawen Kabupaten Semarang. Jurnal Budaya Nusantara. Vol. 4, No. 1, Hal 190-197.

Soetarto, E., \& Sihaloho, M.

Modul 1: Desa dan Kebudayaan Petani. Modul Universitas Terbuka. http:// repository.ut.ac.id/4389/1/LU HT4208-M1.pdf. Diakses Desember 2020 pukul 12.00 WITA.

SugIYONO.

2016. Metode Penelitian Kuantitatif, Kualitatif, dan R\&D. Bandung: PT Alfabeta.

SUMANTRI.

1980. Pengantar Agronomi.

Jakarta: PT Gramedia. 